\title{
Effectiveness of Autogenous Tooth Bone Graft Combined with Growth Factor: Prospective Cohort Study
}

\author{
Kyo-Jin Ahn¹, Young-Kyun Kim¹, Pil-Young Yun¹, Bu-Kyu Lee² \\ ${ }^{1}$ Department of Oral and Maxillofacial Surgery, Section of Dentistry, Seoul National University Bundang Hospital, \\ Seongnam, ${ }^{2}$ Department of Oral and Maxillofacial Surgery, Section of Dentistry, Asan Medical Center, Seoul, Korea
}

Purpose: Autogenous tooth bone graft is proven to be efficient. We evaluated the bone healing effect and clinical capabilities of autogenous tooth bone materials as a scaffold when growth factor is used together with this material. Materials and Methods: Subjects were those who needed implant placement and bone graft because of missing tooth or alveolar bone defect and who kept their autogenous tooth or needed extraction of other tooth. Group I included autogenous tooth bone graft with growth factor, whereas Group II had only autogenous tooth bone graft. We investigated the bone healing state through computed tomography taken just before surgery and 3 to 4 months after surgery to evaluate the effectiveness of bone graft. Group I had 9 patients, whereas Group II had 5 patients. We compared the pre- and post-operative increase of the Hounsfield unit and bone height by analyzing the computed tomography images.

Result: Sinus bone grafts numbered 8 cases, and vertical ridge augmentation was performed together with 3 cases of these. Vertical ridge augmentation was performed in 2 cases, and horizontal ridge augmentation in 1 case alone. Socket graft was done in 3 cases. The post-operative mean value of the Hounsfield unit was 960 in Group I and 836.7 in Group II, but the increase was almost similar, i.e., 636.9 in Group I and 634.7 in Group II on the average. Increase of bone height was $7.6 \mathrm{~mm}$ in Group I and $11.1 \mathrm{~mm}$ in Group II on the average. This difference was attributable to the fact that most of the cases were sinus bone graft in Group II.

Conclusion: In this study, we suggest the possibility of autogenous tooth bone graft materials as a scaffold besides their bone healing ability.

Key Words: Autologous; Bone; Growth; Tooth

Corresponding Author: Young-Kyun Kim

Department of Oral and Maxillofacial Surgery, Section of Dentistry, Seoul National University Bundang Hospital, 82 Gumi-ro 173beon-gil, Bundang-gu, Seongnam 463-707, Korea

TEL : +82-31-787-7541, FAX : +82-31-787-4068, E-mail : kyk0505@snubh.org

Received for publication November 18, 2013; Returned after revision December 12, 2013; Accepted for publication December 19, 2013 Copyright (C) 2013 by Korean Academy of Dental Science

(C) This is an open access article distributed under the terms of the Creative Commons Attribution Non-Commercial License (http://creativecommons.org/licenses/ by-nc/3.0) which permits unrestricted non-commercial use, distribution, and reproduction in any medium, provided the original work is properly cited. 


\section{Introduction}

Although autogenous bone graft is the most ideal technique for the reconstruction of bone defect, it needs a secondary donor site and has a limit in its collection amount. Therefore, allogenic, xenogenic, and alloplastic bone graft materials have been developed and now being clinically applied. But, as this substitute bone lacks osteogenetic ability compared to autogenous bone, tissue engineering research about various growth factors and stem cell for the improvement of bone healing ability is actively conducted ${ }^{1-4)}$. The clinical effectiveness of autogenous tooth bone graft, which was domestically developed in 2008 and now being actively used, was already proved. Also, it was reported that it showed the similar healing state to free autogenous bone graft as its osteoconductive and osteoinductive healing were excellent and bone remodeling was $\operatorname{good}^{5-7)}$.

Meanwhile, although tissue engineering research using various growth factors, bone morphogenic protein, and stem cell, etc is actively being performed worldwide, the appropriate scaffold to carry them have not been developed much. The purpose of this study is to evaluate clinical usability of autogenous tooth bone graft material as the scaffold for polydeoxyribonucleotide (PDRN), one of growth factors which is already being clinically used.

\section{Materials and Methods}

\section{Patients}

This study was conducted under the institutional review board approval (No. E-1203-072-001) of Seoul National University Bundang Hospital.

\section{1) Inclusion Criteria}

(1) Adult patients (more than 18 years old) whose jaw bones have been completely grown.

(2) The patients whose health of the whole body is good and the patients who have controllable medical disease.

(3) The patients who have stored their extracted tooth or need extraction of tooth in the part irrelevant to surgical site out of the patients who need implant placement or bone grafting because of tooth missing and alveolar bone defect.

(4) The patients who have no temporomandibular abnormality or unstable occlusal interference.

(5) The patients who are clearly motivated to have implant.

(6) The patient who agreed on participating in clinical test and signed the informed consent.

\section{2) Exclusion Criteria}

(1) Pregnant patients.

(2) The patients who have uncontrollable medical disease.

(3) Psychologic patients or the people whose mental illness is suspected.

(4) The cases where tester judges that the participation in clinical test is inappropriate ethically and can influence the result of the test.

(5) The patients who are difficult to have implant placement (ex: bruxism or no space for prosthetic appliance, etc).

\section{3) Materials}

\section{(1) Autogenous tooth bone graft material}

The extracted teeth were immersed in $70 \%$ ethyl alcohol and delivered to a specialized treatment company, where any soft tissues, calculus, and foreign materials (e.g., prostheses and endodontic filling materials) attached to the teeth were removed, while the crown and the root portions of the teeth were divided and crushed. Particle sizes ranged from 0.5 to $1.0 \mathrm{~mm}$. The crushed tooth particles were added to a solution of distilled water and hydrogen oxide, and were later washed by ultrasonography washer to remove residual foreign materials. The washed tooth particles were dehydrated with ethyl alcohol solution and defatted 
with ethyl ether solution. Subsequently, after the lyophilization procedure, the tooth particles were sterilized with ethylene oxide gas and packaged as 2 types of materials (AutoBT crown and AutoBT root, AutoBT; Korea Tooth Bank, Seoul, Korea). Autogenous tooth block was also manufactured with a similar method. But, it was manufactured after root portion was partially demineralized without crushing after crown and root portion were separated $^{8)}$ (Fig. 1).

(2) Polydeoxyribonucleotide

One ampule $(3 \mathrm{ml})$ contains PDRN (Placentex ${ }^{\circledR}$; Inthesys 2000, Milano, Italy) of $5.625 \mathrm{mg}$ (Fig. 2).

\section{4) Test Group Allocation}

Twenty-six testees of this study were set and treatment list was prepared. And testee identifying code was handed out in the order the testees come to hospital. According to the list, 14 people were allocated to test group and 12 people to control group but total 17 people participated in screening during testee recruitment period. One of them was excluded from test subjects and the rest 16 people participated in clinical test. But one person was excluded from research subject because of random assignment error (the person was allocated to control group, but operator mistook the person for test group and performed surgery).
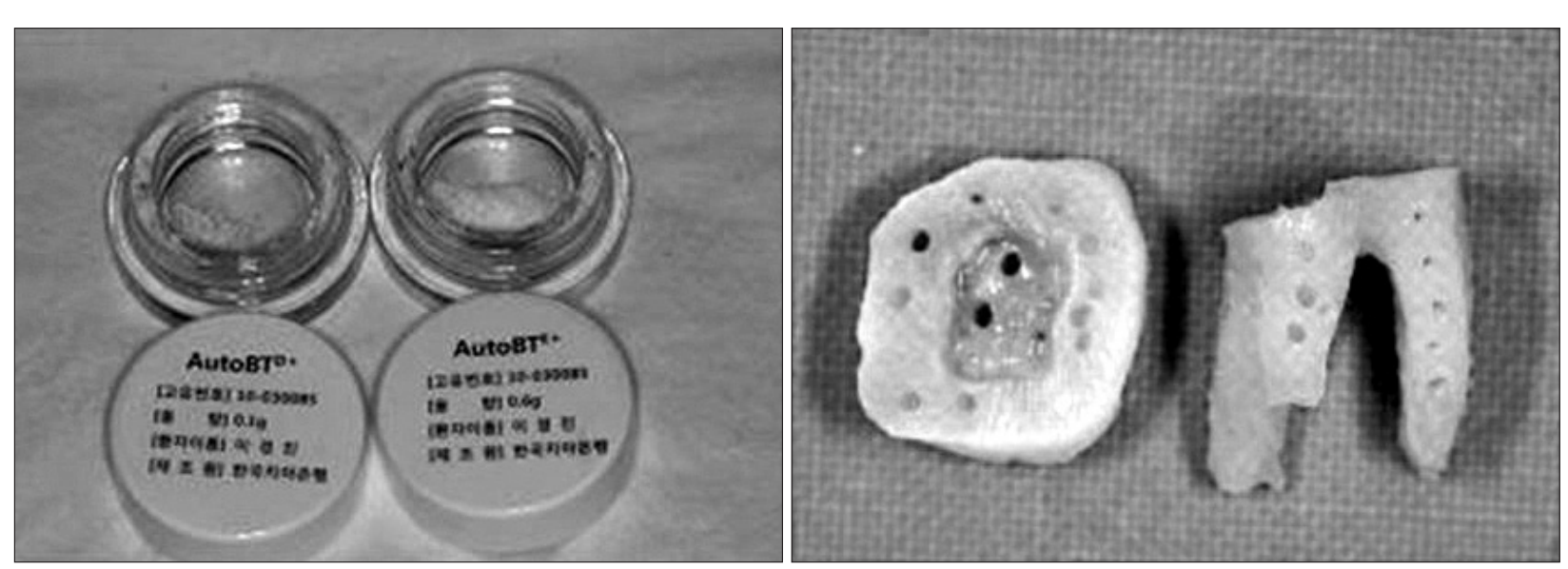

Group I (test group): prepared autogenous tooth bone graft material (powder and block) is hydrated for 5 minutes in PDRN solution and then bone graft is performed.

Group II (control group): powder or block type autogenous tooth bone graft is alone transplanted.

\section{5) Surgical Procedure}

Before surgery, radiography and computed tomography (CT) scan were done. Bony defect was exposed by performing mucoperiosteal incision and flap elevation under local anesthesia using 2\% lidocaine $\mathrm{HCl}$ ( 1 : 100,000 epinephrine). According to test list, AutoBT powder or block was hydrated for 5 minutes in PDRN solution and then was

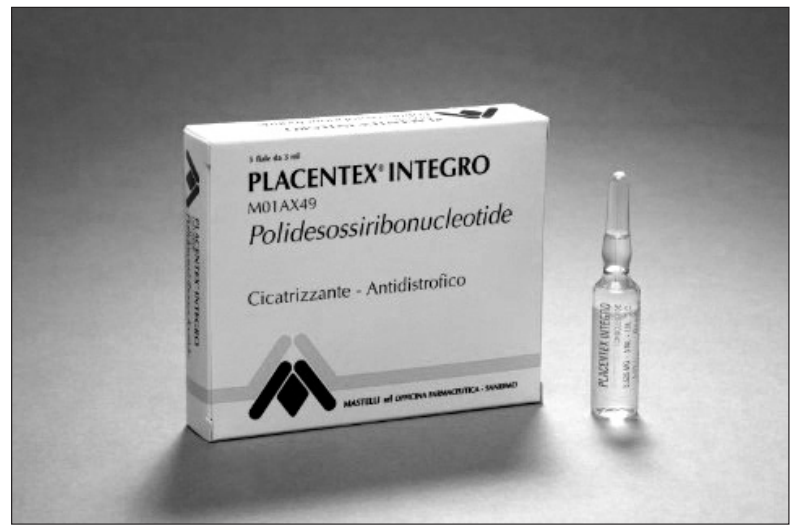

Fig. 2. Placentex ${ }^{\circledR}$ (Inthesys 2000).

Fig. 1. AutoBT powder and block (Korea Tooth Bank). 

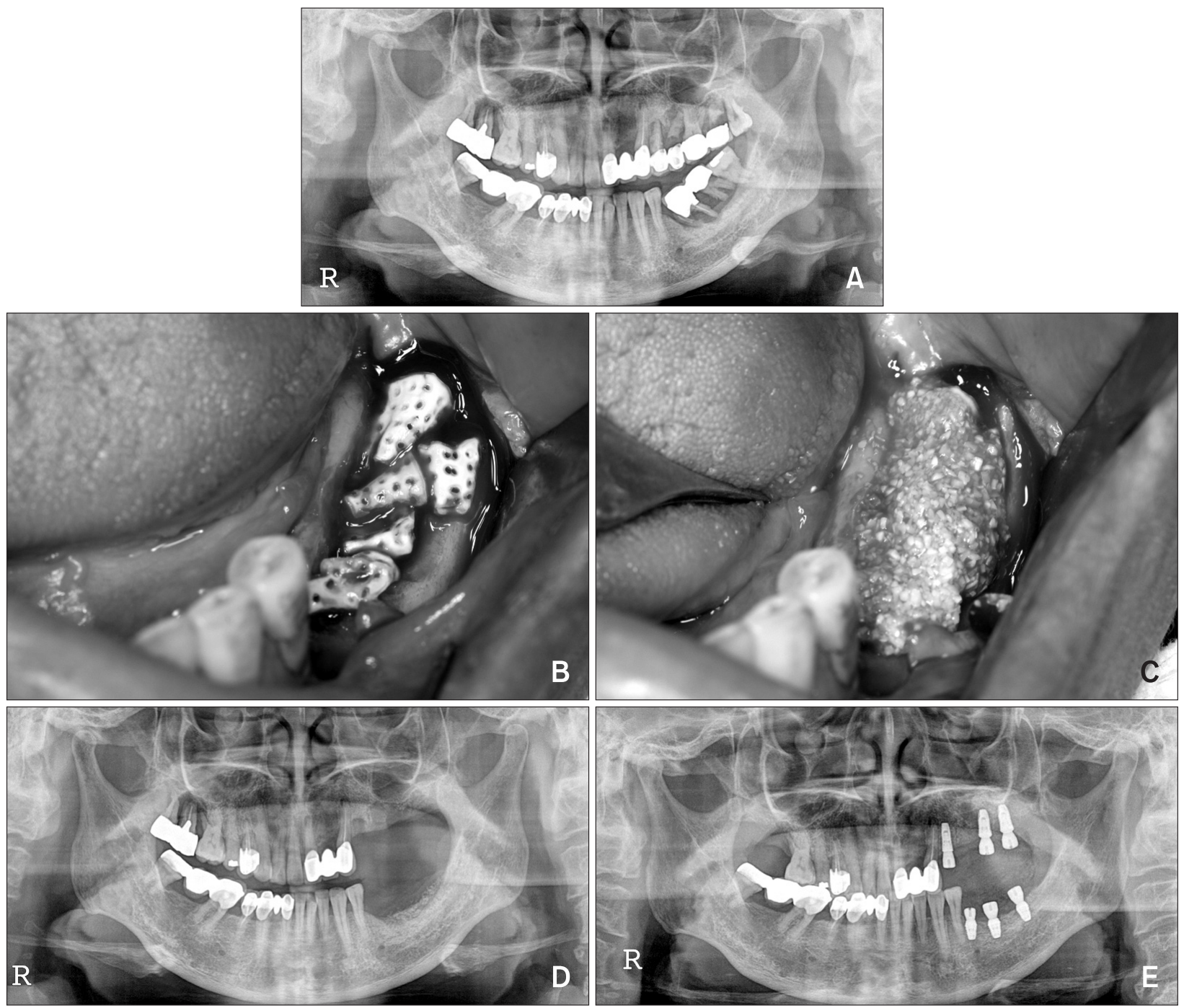

Fig. 3. The case where vertical ridge augmentation was performed in female patient, aged 57 using AutoBT (Korea Tooth Bank) block and powder combined with polydeoxyribonucleotide (PDRN). (A) Panoramic radiograph in first diagnosis. AutoBT block and powder was extracted after the extraction of three left mandibular molars. (B) PDRN-soaked AutoBT block was transplanted. (C) PDRN-soaked powder was transplanted upwards AutoBT block. (D) Panoramic radiograph 3 months after ridge augmentation. (E) Panoramic radiograph after implant placement. Alveolar ridge augmentation effect was excellent and excellent implant primary stability was obtained.

transplanted into Group I. And AutoBT powder or block was alone transplanted into Group II. After suturing the surgical site, antibiotic and antiinflammatory analgesic drug were administered and chlorhexidine gargling was performed. And the suture was removed 7 to 10 days after surgery (Fig. 3).

\section{6) Observation}

Panoramic radiograph was taken immediately after surgery and postoperative complication was observed during the healing period. Bone graft increase and bone density of bone graft area were measured through CT 3 to 4 months after bone graft (Fig. 4). For bone density, Hounsfield unit (HU) was measured in random 3 areas and then average value was found. Bone increase was measure and evaluated in the same area both before surgery and 3 to 4 months after surgery. In the cases where implant was placed, primary stability was 
measured using Osstell Mentor devied (Integration Diagnostics AB, Gothenburg, Sweden) and primary failure rate was investigated.

\section{Result}

One of 15 patients who participated in clinical test could not had CT scan 3 to 4 months after surgery
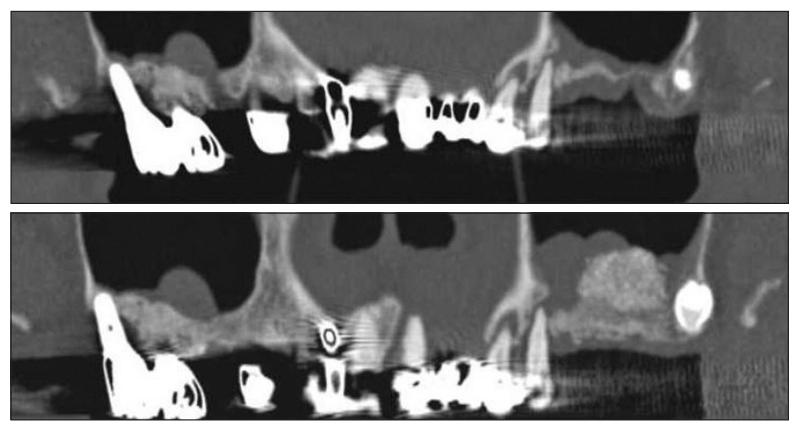

Fig. 4. Computed tomography scan picture before and 3 months after surgery of sinus bone graft surgery using AutoBT (Korea Tooth Bank) powder in male patient, aged 70. Residual bone Hounsfield unit (HU) before surgery was 342.3, and sinus bone graft area $\mathrm{HU}$ after surgery was 959.7. Average bone increase was $14.5 \mathrm{~mm}$. for personal reasons. As a result, 9 people in Group I and 5 people in group 5 were subject of analysis in this study.

Surgical sites were 1 maxillary anterior tooth, 9 maxillary posterior teeth, 1 mandibular anterior tooth, and 3 mandibular posterior teeth. The average age of patients was 52.1 years old (21 to 75 years old) and male and female were 7 people each. Group I consisted of 3 males and 6 females and its average age was 52.1 years old (21 to 75 years old). And Group II consisted of 4 males and one female and its average age was 52.2 years old ( 43 to 71 years old).

The period from surgery to the 2nd CT scan was regarded as healing period and the whole average healing period was $3.7 \pm 0.5$ months (3.0 to 4.3 months).

Unusual complications such as postoperative wound dehiscence or infection were not found in every patient.

Vertical ridge augmentation was performed alone in 2 cases and performed with sinus bone graft in 3 cases. Horizontal ridge augmentation was performed in one case and sinus bone graft was

Table 1. Patient summary

\begin{tabular}{|c|c|c|c|c|c|c|c|c|c|c|c|}
\hline No. & Group & $\begin{array}{l}\text { Age } \\
(y r)\end{array}$ & Gender & Surgery & $\begin{array}{c}\text { Pre-Op. } \\
\text { HU }\end{array}$ & $\begin{array}{c}\text { Post-Op. } \\
\text { HU }\end{array}$ & $\begin{array}{c}\text { Change of } \\
\mathrm{HU}\end{array}$ & $\begin{array}{c}\text { Pre-Op. } \\
\text { bone height } \\
(\mathrm{mm})\end{array}$ & $\begin{array}{c}\text { Post-Op. } \\
\text { bone height } \\
(\mathrm{mm})\end{array}$ & $\begin{array}{l}\text { Increase of } \\
\text { bone height } \\
(\mathrm{mm})\end{array}$ & $\begin{array}{l}\text { Healing } \\
\text { time } \\
\text { (mo) }\end{array}$ \\
\hline 1 & I & 57 & $\mathrm{~F}$ & VR & 265.0 & 933.3 & 668.3 & 0.9 & 6.3 & 5.4 & 4.2 \\
\hline 2 & I & 21 & $\mathrm{~F}$ & $\mathrm{HR}$ & 631.7 & 981.0 & 349.3 & 9.7 & 11.1 & 1.4 & 4.1 \\
\hline 3 & I & 47 & $\mathrm{~F}$ & $S$ & 485.3 & 806.7 & 321.3 & 1.1 & 11.9 & 10.8 & 4.2 \\
\hline 4 & I & 58 & $\mathrm{~F}$ & VR & 68.0 & 781.3 & 713.3 & 19.3 & 26.0 & 6.6 & 4.0 \\
\hline 5 & I & 54 & $M$ & S & 443.3 & $1,049.3$ & 606.0 & 1.7 & 9.5 & 7.7 & 3.7 \\
\hline 6 & I & 51 & $M$ & Sk & 85.0 & $1,097.3$ & $1,012.3$ & 6.6 & 14.7 & 8.0 & 3.3 \\
\hline 7 & I & 75 & $\mathrm{~F}$ & Sk & 276.7 & 912.3 & 635.7 & 1.1 & 8.6 & 7.4 & 3.1 \\
\hline 8 & I & 68 & M & $S+V R$ & 276.3 & $1,021.7$ & 745.3 & 1.3 & 13.5 & 12.2 & 3.5 \\
\hline 9 & I & 38 & $\mathrm{~F}$ & $S+V R$ & 376.7 & $1,056.7$ & 680.0 & 1.3 & 10.4 & 9.1 & 3.0 \\
\hline 10 & II & 45 & M & Sk & 217.7 & 824.7 & 607.0 & 15.9 & 21.8 & 5.9 & 4.2 \\
\hline 11 & II & 44 & $M$ & S & 142.7 & 795.0 & 652.3 & 1.4 & 12.7 & 11.3 & 3.2 \\
\hline 12 & II & 43 & $M$ & S & 121.7 & 585.0 & 463.3 & 1.2 & 9.8 & 8.7 & 3.8 \\
\hline 13 & II & 71 & $M$ & $S+V R$ & 342.3 & 959.7 & 617.3 & 2.1 & 16.6 & 14.5 & 3.0 \\
\hline 14 & II & 58 & $\mathrm{~F}$ & $S$ & 186.0 & $1,019.3$ & 833.3 & 4.1 & 19.2 & 15.0 & 4.3 \\
\hline
\end{tabular}

Op.: operative, HU: Hounsfield unit, F: female, M: male, VR: vertical ridge augmentation, HR: horizontal ridge augmentation, S: sinus graft, Sk: soket graft. 
Table 2. Change of bone height and Hounsfield unit (HU)

\begin{tabular}{ccccccc}
\hline Group & Pre-Op. HU & Post-Op. HU & Change of HU & $\begin{array}{c}\text { Pre-Op. } \\
\text { bone height (mm) }\end{array}$ & $\begin{array}{c}\text { Post-Op. } \\
\text { bone height (mm) }\end{array}$ & $\begin{array}{c}\text { Increase of } \\
\text { bone height (mm) }\end{array}$ \\
\hline I & 323.1 & 960.0 & 636.9 & 4.8 & 12.4 & 7.6 \\
II & 202.1 & 836.7 & 634.7 & 4.9 & 16.0 & 11.1 \\
\hline
\end{tabular}

Op.: operative.

Values are presented as mean.

performed alone in 5 cases. And socket graft was performed in 3 cases (Table 1). Bone density after surgery was average $960.0 \mathrm{HU}$ in Group I and 836.7 HU in Group II and thus Group I was higher but the increase from before surgery was similar in two groups as 636.9, and 634.7. Average bone increase after surgery was $7.6 \mathrm{~mm}$ in Group I and $11.1 \mathrm{~mm}$ in Group II (Table 2).

Total 23 implants were placed and all implants were delayed implantation except one. Primary implant stability quotient (ISQ) was average 61.8 \pm 16.7. For Group I, total 13 implants were placed and primary implant stability quotient was average $66.8 \pm 11.5$. For Group II, total 10 implants were placed and primary implant stability quotient was average 55.9 \pm 20.4 . There was no failed implant during observation period.

\section{Discussion}

Recently, many researchers are interested in the importance of extracellular nucleotides and nucleosides which stimulate the cell growth. One experiment showed that PDRN, the mixture of DNA polymers with different lengths, stimulated fibroblasts and collagen and it is assumed that is because of its stimulation on purinergic receptor system. PDRN was licensed as Medicine and medical supplies in some countries including Europe and now is used for wound healing and beauty treatment. Product sold in market today has Placentix ${ }^{\circledR}$ (includes PDRN $5.625 \mathrm{mg}$ in 1A 3 $\mathrm{ml})$. PDRN is helpful for normal matrix formation by shortening the healing period through its prompt tissue regeneration and wound healing and by promoting the creation of collageneous / noncollageneous protein. Also, it is characterized by being effective in tissue regeneration by promoting cell regeneration in cellular stage ${ }^{9-14)}$.

In 2008, an autogenous bone graft material was developed from extracted teeth, and subjected to many basic and clinical studies. It has since been found to be an excellent biocompatible material with osteoinductive and osteoconductive potential $^{5-8,15,16)}$. Researches that demineralized dentin matrix (DDM) can play a role as the scaffold of bone morphogenic protein (BMP) and growth factors were announced. In other words, DDM has inorganic components, which is the most smilar to autogenous bone, and includes organic components engaged in osteoinduction. DDM has microporous structures named dentinal tubules that could be loaded with bone growth factors such as $\mathrm{BMP}^{15,17-20)}$. In other words, it is con-sidered DDM can play the role of excellent bone graft material and also of carrier of growth factors.

Therefore, we conducted this clinical research to evaluate the clinical effectiveness and safety of the mixture of PDRN, which became commercialized and is being clinically used as one of growth factors, and DDM powder or block. In this study, vertical and horizontal ridge augmentation, sinus bone graft, and extraction socket graft were used alone or multiply. In both groups, bone increase effect was observed and bone density was increased 3 to 4 months after surgery. But because of various variables, we can draw statistically significant 
result. In the cases where implant was placed after bone graft, relatively good primary implant stability was obtained, and there was no failed implant during the short observation period. Also, there was no complication after bone graft such as infection or wound dehiscence.

The limit of this study is that there were many patients halfway dropped out during the passage observation after random allocation. The reason of halfway drop-out was that many patients had implant surgery in other hospitals although they participated in bone graft for this study and most of them rejected the followup observation. Therefore, the number of patients, the subject of clinical research, was small and there was no balance between the numbers of test group and control group. Also, statistical significance could not be found and significant bone increase effect could not be assessed because of its application on various techniques. But this study is meaningful in that the mixture of DDM and PDRN can give good result showing no clinical complication. In the future, we need to find significant effect when we add growth factors through histomorphometric research after increasing the subject of research and collecting tissue specimen.

\section{Conclusion}

There were no postoperative complications, and favorable implant primary stability was obtained after bone graft. Therefore, based on this study, we suggest the possibility of using autogenous tooth bone materials as scaffold besides their bone healing ability. We will report histologically comparative study results after supplementing cases in the future.

\section{Acknowledgement}

This study was supported by graft No. 02-2012-007 from the SNUBH Research Fund.

\section{References}

1. Kim YK. Regenerative medicine for the reconstruction of hard tissue defects in oral and maxillofacial surgery. J Korean Assoc Oral Maxillofac Surg. 2012; 38: 69-70.

2. Park BW, Byun JH, Hah YS, Kim DR, Chung IK, Kim JR, Kim UK, Park BS, Kim GC. Expression of vascular endothelial growth factor receptors in tumor and stromal cells of tongue squamous cell carcinoma. J Korean Assoc Oral Maxillofac Surg. 2007; 33: 11-9.

3. Lee JH, Kim CS, Choi KH, Jung UW, Yun JH, Choi $\mathrm{SH}, \mathrm{Cho} \mathrm{KS}$. The induction of bone formation in rat calvarial defects and subcutaneous tissues by recombinant human BMP-2, produced in Escherichia coli. Biomaterials. 2010; 31: 3512-9.

4. Byun JH, Kang EJ, Maeng GH, Rho GJ, Kang DH, Lee JS, Park BW. Maxillary sinus floor elevation using autogenous skin-derived mesenchymal stem cells in miniature pigs. J Korean Assoc Oral Maxillofac Surg. 2010; 36: 87-93.

5. Kim YK, Kim SG, Byeon JH, Lee HJ, Um IU, Lim SC, Kim SY. Development of a novel bone grafting material using autogenous teeth. Oral Surg Oral Med Oral Pathol Oral Radiol Endod. 2010; 109: 496-503.

6. Kim YK. Bone graft material using teeth. J Korean Assoc Oral Maxillofac Surg. 2012; 38: 134-8.

7. Kim YK, Lee J, Um IW, Kim KW, Murata M, Akazawa T, Mitsugi M. Tooth-derived bone graft material. J Korean Assoc Oral Maxillofac Surg. 2013; 39: 103-11.

8. Kim YK, Kim SG, Yun PY, Yeo IS, Jin SC, Oh JS, Kim HJ, Yu SK, Lee SY, Kim JS, Um IW, Jeong MA, Kim GW. Autogenous teeth used for bone grafting: a comparison with traditional grafting materials. Oral Surg Oral Med Oral Pathol Oral Radiol. 2012. [Epub ahead of print]

9. Guizzardi S, Galli C, Govoni P, Boratto R, Cattarini G, Martini D, Belletti S, Scandroglio R. Polydeoxyribonucleotide (PDRN) promotes 
human osteoblast proliferation: a new proposal for bone tissue repair. Life Sci. 2003; 73: 1973-83.

10. Sini P, Denti A, Cattarini G, Daglio M, Tira ME, Balduini C. Effect of polydeoxyribonucleotides on human fibroblasts in primary culture. Cell Biochem Funct. 1999; 17: 107-14.

11. Thellung S, Florio T, Maragliano A, Cattarini G, Schettini G. Polydeoxyribonucleotides enhance the proliferation of human skin fibroblasts: involvement of A2 purinergic receptor subtypes. Life Sci. 1999; 64: 1661-74.

12. Bitto A, Galeano M, Squadrito F, Minutoli L, Polito F, Dye JF, Clayton EA, Calò M, Venuti FS, Vaccaro M, Altavilla D. Polydeoxyribonucleotide improves angiogenesis and wound healing in experimental thermal injury. Crit Care Med. 2008; 36: 1594-602.

13. Galeano M, Bitto A, Altavilla D, Minutoli L, Polito F, Calò M, Lo Cascio P, Stagno d'Alcontres F, Squadrito F. Polydeoxyribonucleotide stimulates angiogenesis and wound healing in the genetically diabetic mouse. Wound Repair Regen. 2008; 16: 208-17.

14. Raposio E, Guida C, Coradeghini R, Scanarotti C, Parodi A, Baldelli I, Fiocca R, Santi PL. In vitro polydeoxyribonucleotide effects on human preadipocytes. Cell Prolif. 2008; 41: 739-54.

15. Kim YK, Lee JK, Kim KW, Um IW, Murata M. Healing mechanism and clinical application of autogenous tooth bone graft material. In: Pignatello R, ed. Advances in biomaterials science and biomedical applications [Internet]. Rijeka, Croatia: InTech; 2013 [cited 2013 Mar 3]. Available from: http://www.intechopen.com/books / references/advances-in-biomaterials-science-and- biomedical-applications/healing-mechanism-andclinical-application-of-autogenous-tooth-bonegraft-material.

16. Kim YK, Lee HJ, Kim KW, Kim SG, Um IW. Guide bone regeneration using autogenous teeth: case reports. J Korean Assoc Oral Maxillofac Surg. 2011; 37: 142-7.

17. Murata M, Akazawa T, Mitsugi M, Um IW, Kim KW, Kim YK. Human dentin as novel biomaterial for bone regeneration. In: Pignatello R, ed. Biomaterials: physics and chemistry [Internet]. Rijeka, Croatia: InTech; 2011 [cited 2011 Nov 1]. Available from: http://www.intechopen.com/ books / biomaterials-physics-and-chemistry / human-dentin-as-novel-biomaterial-for-boneregeneration.

18. Murata M, Akazawa T, Mitsugi M, Kabir MA, Um IW, Minamida Y, Kim KW, Kim YK, Sun $\mathrm{Y}$, Qin C. Autograft of dentin materials for bone regeneration. In: Pignatello R, ed. Advances in biomaterials science and biomedical applications [Internet]. Rijeka, Croatia: InTech; 2013 [cited 2013 Mar 3]. Available from: http://www.intechopen. com/books/advances-in-biomaterials-scienceand-biomedical-applications / autograft-of-dentinmaterials-for-bone-regeneration.

19. Kim JY, Kim KW, Um IW, Kim YK, Lee JK. Bone healing capacity of demineralized dentin matrix materials in a mini-pig cranium defect. J Korean Dent Sci. 2012; 5: 21-8.

20. Kim YK, Kim SG, Oh JS, Jin SC, Son JS, Kim SY, Lim SY. Analysis of the inorganic component of autogenous tooth bone graft material. J Nanosci Nanotechnol. 2011; 11: 7442-5. 